\title{
The use of dependence structure matrix and domain mapping matrix in managing uncertainty in multiple project situations
}

\author{
Mike Danilovic ${ }^{\mathrm{a}, *}$, Bengt Sandkull ${ }^{\mathrm{b}, 1}$ \\ a Jönköping International Business School, Jönköping University, P.O. Box 1026, SE-551 11 Jönköping, Sweden \\ ${ }^{\mathrm{b}}$ Malmö University, School of Teacher Education, SE-205 06 Malmö, Sweden
}

Received 21 February 2003; received in revised form 29 June 2004; accepted 17 November 2004

\begin{abstract}
Development of complex products is performed in multi-project environment in which it is crucial to explore interdependencies and manage the uncertainty with the information exchange and the understanding of the context. The purpose of this paper is to introduce a dependence structure matrix and domain mapping matrix approach that enables the systematic identification of interdependencies and relations in a Multi-project environment. These approaches enables clarifications of assumptions, the tractability of dependencies, explores the information needed within and between different departments, projects and people. This creates a transparency and enables the synchronization of actions through transformation of information and exploration of assumptions within and between domains. The outcomes of this process are situational visibility creating direction and accountability and the learning that takes place through communicating, reflecting, understanding, and acting.
\end{abstract}

(C) 2004 Elsevier Ltd and IPMA. All rights reserved.

Keywords: Multiproject; Complexity; Uncertainty; Complex project; Dependence structure matrix; Domain mapping matrix

\section{Introduction}

Product development of complex products is usually organized in many different projects. Each of these projects focuses on different functionality or physical parts of the product. Due to the complexity of the product and the scarcity of resources, projects run concurrently, sequenced, or overlapped, which creates a huge demand for an exchange of information between people in temporary projects, the customers, and the suppliers. This kind of environment may be labeled the multi-project situation. It is characterized by the multitude of interdependencies between projects, tasks and activities, people,

\footnotetext{
${ }^{*}$ Corresponding author. Tel.: +46 36 157588; fax: +46 36161069 .

E-mail addresses: Mike.Danilovic@jibs.hj.se (M. Danilovic), Bengt.Sandkull@lut.mah.se (B. Sandkull).

${ }^{1}$ Tel.: +4646134677.
}

knowledge areas, technologies, products, and components.

No matter how we organize the process for product development, there will always be interdependencies between components, sub-systems, departments, projects, groups, and individuals who need to share information with others to fulfill their tasks. Von Hippel [1], who claims that a characteristic of product development is the partitioning of tasks, activities, or components, recognizes this problem and argues that the character of these interdependencies influences the way in which product architecture is organized into chunks or handled by teams and individuals.

Precisely where the boundaries between such tasks are placed can affect the project outcome and the efficiency of the task performance due to associated changes in the problem-solving interdependence among tasks. The core function of many innovation projects 
and project tasks is precisely problem solving and the generation of new information (Von Hippel [1, p. 407]).

Product development is a process of uncertainty reduction in problem solving. Our approach in this paper emphasizes uncertainty as the normal state we have to face. The crucial issue of uncertainty is to understand who needs information, what kind of information is needed, why and when, and to find ways to share and exchange information with others. If information is not available when it is needed the level of uncertainty is increased as assumptions are needed to be made. This view stresses the need for other principles than those established that will promote management of uncertainty by creating organizational settings to achieve a high degree of coordination and integration in the problem solving. Communication and the flow of information in product development need in product development to take into account the mesh of relations and interdependencies characteristic already in a single project but crucial in a Multi-project environment.

In this paper, we consider complexity as originating from three major sources: the functionality of a product, chosen technology, and people involved. These three dimensions are interwoven creating uncertainty that management has to handle in project management and organization. The traditional approach to manage the complexity of a product is by systematic decomposition of a product into components and elements or an organization into departments, and by integrating components into chunks and sub-systems and people into projects and teams $[2,3]$. Breaking down a complex system or integrating items requires assumptions about the content, interfaces between items and interdependencies. All assumptions involve risk taking and produce uncertainty. Justified needs for reappraisal of assumptions may be avoided. Once you have done the work based on a set of assumptions, you must test whether the assumptions were correct. If you do not know what assumptions you have made, you are in trouble. If you do not even recognize that you have made any assumptions, you are in a heap of trouble [4]. One of the most important characteristics of product development is that the process is not linear; it rather encompasses cyclic and iterative phases [5]. These phases can bring new ideas into the process, or create rework due to wrong assumptions and change of requirements, or they create new knowledge.

The purpose of this paper is to present an approach based on the systematic analysis of interdependencies and relations, the dependence structure matrix (DSM) and domain mapping matrix (DMM). These approaches focus on understanding interdependencies between items, components, organizations, teams, or people, in terms of the need for the information exchange to manage uncertainty through exploring assumptions within one or between different domains in product develop- ment. Applying multi-dimensional DSM and DMM analysis will show how this approach might affect working in multi-project situation performing the product development of complex systems within one project, between a project and the basic organization and between a project and other interrelated projects.

\section{Approaches to complexity in product development}

\subsection{Current approaches to multi-project situations}

The traditional approach to project management is to consider projects as being independent of each other. Recently, the multi-project situation has been recognized as a major issue for corporations and the focus in research has shifted towards the multi-project situation. Several authors have attempted to create an increased understanding of the multi-project situation. Some indicators suggest that up to $90 \%$ (by value) of all projects are conducted in a multi-project context. The vast majority of these projects share resources with other projects and thus the major issue is finding ways of handling the resource scarcity according to the overall strategic direction of the corporation [6].

However, there is a need to find a balance between the focus applied in one particular project and the long-term strategy in a stream of different projects in which differences in goals, visions, and direction may be seen between projects and long-term strategy [6] Hendrix et al. [7] found the multi-project situation as a problem of allocation of scarce resources (i.e., people) to a diversified project portfolio. They suggest flexible resource planning taking into account the availability of scarce resources and the need for special knowledge. The multi-project situation is seen by Grey [8] as a nominal umbrella grouping of projects mainly on the basis of interdependencies among projects, sub-projects, or any kind of project-type work activity. Grey suggests that these interrelationships need to be recognized in terms of vertical and horizontal relationships to create proper coordination of project-type work among different projects. The issue of interrelationships between organizations, individuals and projects is also recognized by van der Merwe [9], who suggests a similar solution with the coordination of activities among projects in a matrix-based analysis. The relations between projects are recognized by Payne [10] and Ghomi and Ashjari [11] as a major problem with choice of technical solutions, cost and resource planning, and control.

In our view, complexity itself should be understood as an analytical issue, while the effects it creates in terms of uncertainty need to be seen as the issue facing management. Management does not normally deal with complexity itself, but the impact of complexity in terms of uncertainty. When management designs the basic 
organization as well as temporary project structures, define the processes in the product development, organize tasks and activities in project planning, work breakdown structure and work packages, choose technology and decide the features of the next product to keep up with the time schedule, uncertainty is the issue. Management decisions and actions are based on set of assumptions, implicit or explicit. The levels of assumptions define the level of uncertainty.

\subsection{Basic dimensions of complexity and uncertainty in product development}

We consider that the nature of the work being carried through is the prime source of complexity to meet the product specifications and the functional demands on technical solutions [12]. Complexity in product development can be understood in terms of the technology underlying a product, the technology chosen for components and technical sub-systems in the product architecture, and the corporate and social context in which product development takes place. Complexity is a number of items interconnected by a multitude of relations and dependencies between people, their tasks and activities [13-17]. Complexity is determined by the interdependencies between people, technology, and functionality although some researchers claim that complexity resides in the minds of people! In that perspective, complexity is a consequence of our perceptions and interpretation of the situation. Product architecture is the basis for creating a task structure and activities to be performed by engineers. The structure of the task is a series of actions that people have to perform and that essentially constitute the development process leading to an end product. If we can analyze the task structure according to the relations between product structure and task structure, we may achieve the information needed to redefine the product structure. This new product structure may help us create a different process, i.e., a set of tasks in a task structure that is more efficient in terms of time, cost, and performance.

Uncertainty refers to the variation of items or elements upon which work is performed and the unpredictable behavior of people. Some measures of uncertainty are based on variability of inputs, the number of exceptions encountered in the work process, and the number of major product changes experienced [12]. As we have pointed out, product development is a process of uncertainty reduction. The risk is a consequence of uncertainties in our assumptions or of uncertainty about future development and events. Risk is actually a measure of uncertainty [18]. The most important aspect of uncertainty is to what degree we can understand assumptions and analyze the information needed to reduce the uncertainty and risk. There are different approaches to risk and uncertainty. Risk management can be handled by quantitative or qualitative approaches. One quantitative approach is based on the mathematical approach focusing on systematic analysis of historic and statistic's data [19]. Other is scenario approach focusing on situations, where it is virtually impossible to specify effects and probability to any reasonable degree of accuracy. In such situations, risk is analyzed through scenario simulations [20]. However, qualitative approach to risk and uncertainty stress that uncertainty is not an objective quantity, not a fixed quantity, nor is it set from possible situations. In such approach uncertainty is socially constructed by the context, rhetorical roles, the assumptions of purpose, and the acceptance of knowledge claims, i.e., how the uncertainties have been constructed by individuals. Such approach stress that uncertainty is constructed and reconstructed by individuals and that this is a social process based on communication, information exchange, and understanding of the social world as well as the rational issues of product development. In this approach, uncertainty arise from ignoring the ignorance as we take various features of a problem as given and focus on other dimensions. Uncertainty is also related to a purpose and goals and the rhetorical context and agency involved [21]. In our approach, we are close to the social constructionist approach stressing that communication and information exchange is crucial for people to understand their own role, the context, the interdependencies to others, to explore and reduce assumptions to handle uncertainty and risk in product development.

\subsection{Complexity and uncertainty in the multi-project situation}

From the discussion of complexity in general, we can see that the most important dimensions that we need to understand concern the sources of complexity: the functionality of a product, chosen technology, and people involved. The traditional reaction by management to complexity is to ignore it $[21,22]$.

Fig. 1 scrutinizes the reasoning above and visualize three major sources of complexity: functionality, technology and people and how they correspond to three major sources of uncertainty: organizational settings, product architecture, and project management.

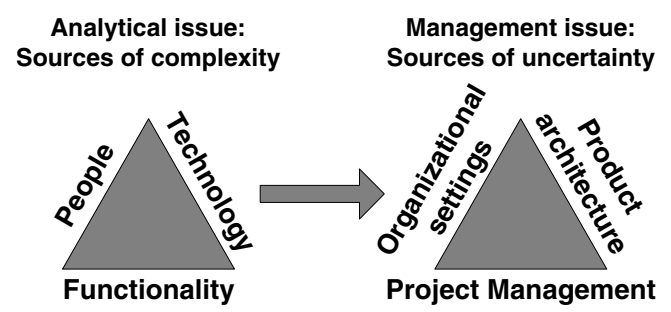

Fig. 1. Complexity and uncertainty in product development. 
The functionality-related source of complexity is related to customer demands, functional requirements, and specifications of the product. This dimension affects project management and goal achievement. The organization of product development concerns the transformation of customer demands and product specifications into product architecture and choices of technological solutions. The project management issue also focuses on how the available knowledge base can be used to find technical solutions that will be feasible in meeting demands on functionality.

The technology-related complexity dimension deals with the product design, which includes the choice of making a product modular or integrated, and all the tasks that, have to be performed in solving the technical problems.

The people-related complexity dimension affects decisions on how to organize people in the temporary project structure and the choice of personnel for the project teams to match the skills available with the demands of each project. In the multi-project situation, a crucial issue is finding a balance between working in projects and developing the long-term technical knowledge of the basic organization. There is still the considerable freedom of choice in a project when technology and project team have been chosen. Work can be done sequentially or in parallel. It can be organized according to some functional logic or to logic of interdependencies. With concurrent engineering a high degree of integration of departments and even suppliers and customers are possible $[16,17]$.

In the multi-project situation, numerous projects aim at different functional solutions using various technologies that need to be coordinated and integrated in the product. In many cases, product development is organized according to the technologies underlying business decisions and separated into different projects. For example, in the automotive industry, one project may concern a truck chassis, another engine and drive line, and a third the electronics, computer hardware and software. Each of these projects is different regarding the chosen technology, the people working in projects and the tasks they perform. What these projects have in common is that the final output is not a question of delivering chassis, engines, computers, or software. The customers want a complete vehicle according to the technical specifications. It is management's responsibility to organize product development in such a way that the products can be delivered on time.

The timing of different projects, the tasks to be performed, and the assignment of people in different organizational setups meeting the functionality demands of the product are possibly the most important tasks that management has to consider, understand, and address. It lies near at hand to consider the multi-project situation floating because of the need to handle shared re- sources and interdependencies between different projects. It is a tricky task for management and even engineers to understand where interdependencies exist and to manage possible conflicts between departments, in the project teams and between departments and project teams.

\section{Application of dependence analysis matrix in a multi- project situation}

\subsection{The dependence structure matrix (DSM) and domain mapping matrix (DMM) approaches}

In this paper, we argue that complexity arises from the relationships and dependencies among items such as product development-related tasks and activities, product functionality, components in a product architecture, and people involved in the process. Variation among and the number of dependencies and relations determines the level of complexity [16,17]. When the level of complexity increases, the level of uncertainty will probably increase as well, because of the need to make assumptions about relationships. The crucial issue is how well we can identify dependencies, understand relations, and explore assumptions to turn assumptions into reasonable facts and thereby reduce uncertainty.

The methodology that is used to represent and analyze dependencies and relations between items is known as DSM or DSM and was introduced by Steward in 1967 [23] and 1981 [24]. These papers are considered as the starting point of the DSM field. The major idea of Steward approach was to handle uncertainty in complex systems by exploring the structure of a problem. This structure is explored in terms of identifying items of the problem structure and finding where and how to make assumptions and make them explicit. The structure of the problem is seen as a spreadsheet showing for each information item needed to solve the problem what other items it directly depends on. These relations are mapped in a matrix. Matrices are used to map a set of items toward itself $(N \times N)$ or to map a set of items toward another set of items $(N \times P)$.

Figs. 2(a) and (b) shows the principles of matrixbased analysis, where the dependencies and relations are plotted in rows and columns. Fig. 2(a) shows three types of dependencies and how these three are represented traditionally in a graph and how they are represented in a DSM matrix. Fig. 2(b) shows how information flow among six items can be represented in a flow graph and how they can be represented in a DSM matrix representation. The DSM represents and visualizes interdependencies and relations between items such as tasks and activities, components and sub-systems, and among people and teams. 


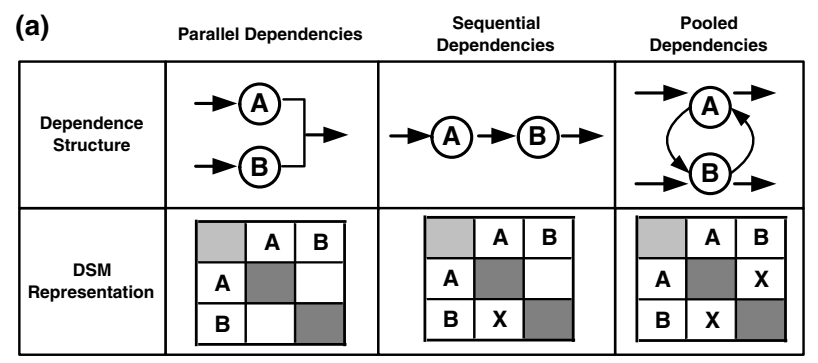

(b) FLOW REPRESENTATION

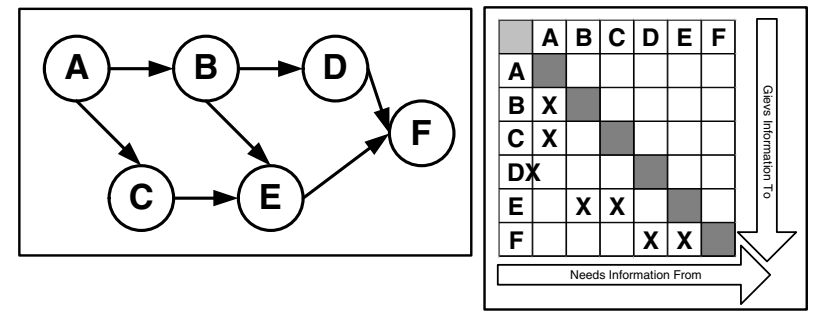

Fig. 2. (a) Typologies of dependence structures vs. DSM representation of dependences. (b) Graph representation of information flow vs. DSM representation of information flow.

A DSM analysis shows how the design of tasks, sequencing of activities can be organized for the effective problem solving in team-based work and the communication required within and between teams $[25,26]$. The information captured in a DSM analysis is similar to that in a directed graph or a PERT chart. However, the matrix representation makes it possible to create a more comprehensive model of the information flow and interdependency analysis in describing and analyzing complex projects. Unlike the PERT technique, DSM allows tasks to be coupled or independent.

The initial Steward approach was based on onedimensional, square, matrixes focusing on activities. In such a matrix, the analytical focus is to identify dependencies and relations between items to rearrange these items to find the most efficient way of sequencing tasks or activities. The partitioning algorithm used is moving identified dependencies below the diagonal line. All dependencies left above the diagonal are assumptions that may lead to rework and feedback loops.

Over the years the original Steward approach has been modified. Researchers at Massachusetts Institute of Technology in Boston introduced new dimensions in the analysis such as tasks [27], information flow [28], product parameters, product functionality, and product architecture [2], people and organizationalbased analysis [29], [30]. An extensive DSM literature summary is presented by Browning [31]. However, both the Steward and MIT approaches were based on square matrixes. This means that analyses of dependencies were one-dimensional, or in one product development domain. Browning [31] provided a taxonomy of these approaches and identified two discriminating dimensions related to whether the DSM represented static or timebased (temporal) dependences. While Browning's taxonomy identified four types of DSM applications in these two dimensions and hypothesized additional applications and relationships, the analysis focuses on individual domains represented by square matrices.

In 2001, Danilovic presented studies of dependencies between dual domains in product development. These dual domain and matrix-based analyses are called DMM [32]. The DSM/DMM approaches are complementary to each other. While the first focus on one domain the other one focus on interactions between domains.

- $N \times N$ approach is named DSM,

- $N \times P$ approach is named DMM.

In 2001, Danilovic introduced DMM studies on product architecture vs. organization and in another paper the same year a study on Systems vs. Organization [33,34]. In 2003, another DMM study was presented [35]. In this study, several DMM analysis was introduced, Product requirements vs. Functional requirement, Functional requirement vs. Product architecture, Product requirement vs. Product specifications, and Functional requirement vs. Product specifications, and Product specifications vs. Product architecture. In 2003, Maurer and co-workers [36] showed one example of a DMM analysis focusing on domains of product architecture and customer requirements.

This study presented in this paper introduces a dynamic approach to product development by synchronizing two DSM and one DMM analysis to each other. In real life, practitioners are dealing with uncertainty in several dimensions simultaneously. As we suggest in Fig. 1, uncertainty is about issues of how to organize people in the basic organization and in many different simultaneously ongoing projects, how to organize people in specific project teams such as an engine project, gearbox project, etc., and finally how to manage the process in the developing complete systems, i.e., how to organize the Multi-project environment and how to coordinate people and integrate their tasks in many inter-related projects. To manage all these dimensions, we have introduced two one-domain DSM analysis in the domains of basic organization and one engine project and we have introduced one DMM analysis in the Multi-project environment. The dynamics come from the synchronization between these domains and between DSM and DMM analysis.

\subsection{A case using action research}

The research approach underlying this paper is an experiment using two DSM and one DMM analysis in a real case. We were actively involved in initiating a 
process of developing a new truck program in close collaboration with one large truck manufacturing corporation. This corporation had just started up a series of inter-related projects aiming at developing new truck engines, gearboxes, chassis, drive lines, and cabins. The demands on management to keep the development within the time schedule and cost level were high. There was a need to avoid rework resulting from a lack of understanding of the complex situation and inadequate communication among people within the project and in other related projects, as well as between projects and other parts of the basic organization.

Using the DSM and DMM approach, we were able to intervene in the organizing of one engine project within a multi-project situation of 10 other projects and a functionally organized base organization. We performed this study in one seminar and divided 60 persons into three groups that simultaneously performed the DSM/ DMM analysis. The empirical data collected were then used to reflect upon the issues of the multi-project situation in which management and engineers were involved. The final data were given to participants and managers. They together used the data to design communication plans to handle all identified relations and the need for information exchange needed.

\subsection{The organizational premises in development of new truck program}

The experiment was conducted in a real-time situation at a large international truck-manufacturing corporation. One of the characteristics of this corporation is that it has succeeded in modularizing its entire range of trucks. Modularization has made it possible to introduce continuous product development in each of the modules under the assumption that the modules are independent of each other. Some years ago, a major product renewal program was undertaken: new chassis and new truck cabins were developed together with several new engines, gearboxes, and drivelines. At the same time, a higher content of electronics was introduced throughout the entire range of trucks. A great amount of engineering work needed was performed in a dual organization structure.

Fig. 3 is an application of Fig. 1 to the real situation of this truck manufacturing company. Fig. 3 illustrates the multi-dimensional organizing that characterizes the development of new truck program. The top left-hand organizational chart illustrates the prevailing basic organizational structure, which follows the traditional departmental and functional logic. The top right-hand chart illustrates the organizing of engine project. It reflects the product architecture of the engine, as each team is focusing on different physical sections of the engine. The bottom-hand chart illustrates the multi-project situation the truck company faces. The development program is managed by dividing it into a series of different projects.

The basic functional organization has been long in operation. As much as possible of the development work was performed in a temporary project organization utilizing cross-functional teams. The major problem confronting top management was the question of how to organize all the projects simultaneously while each of these comprised different technologies in different modules of the truck system, and how to coordinate all the tasks and activities among people in projects and in the basic organization in order to keep to the time schedule and maintain deliveries to the end customer.

Such a complex situation creates uncertainty in product development for engineers and management. For engineers, it is crucial to understand the product specifications and the functional demands that they have to meet in their engineering work. They are dependent on other people performing other inter-related tasks somewhere else in other projects, departments, or organizations. For management uncertainty appears in product planning and decision-making. How should management delimit one project from another? How should they design the work breakdown structure in order to enable a high level of concurrency and cross-functionality and at the same time keep the balance between the demands made by the basic organization and the temporary organization? How can management keep projects autonomous in order to enhance adaptation to changes and at the same time keep track of the total achievement of specifications and functionality of the final product?

On the project management level, one of the major problems was to develop a communication plan to help people perform their engineering work and keep to the time schedule. For engineers in different projects, there were major tasks in developing skills, keeping track of what different people were doing in different projects and understanding the whole picture of the system of product development for the new generation of trucks in which each person had only a limited role.

\subsection{The application of DSM and DMM in managing uncertainty}

The DSM and DMM approaches were introduced when the truck engine project was initiated. During the kick-off of this project, with approximately 60 people, two DSM and one DMM analyses were conducted in three parallel workshop groups. One group focused on interdependencies between tasks within the engine project, another focused on interdependencies between tasks between the engine project and functional departments within the basic organization, and the third group focused on interdependencies between the engine project and 10 other major projects. The questions asked during the workshops were: WHAT interdependencies can be 


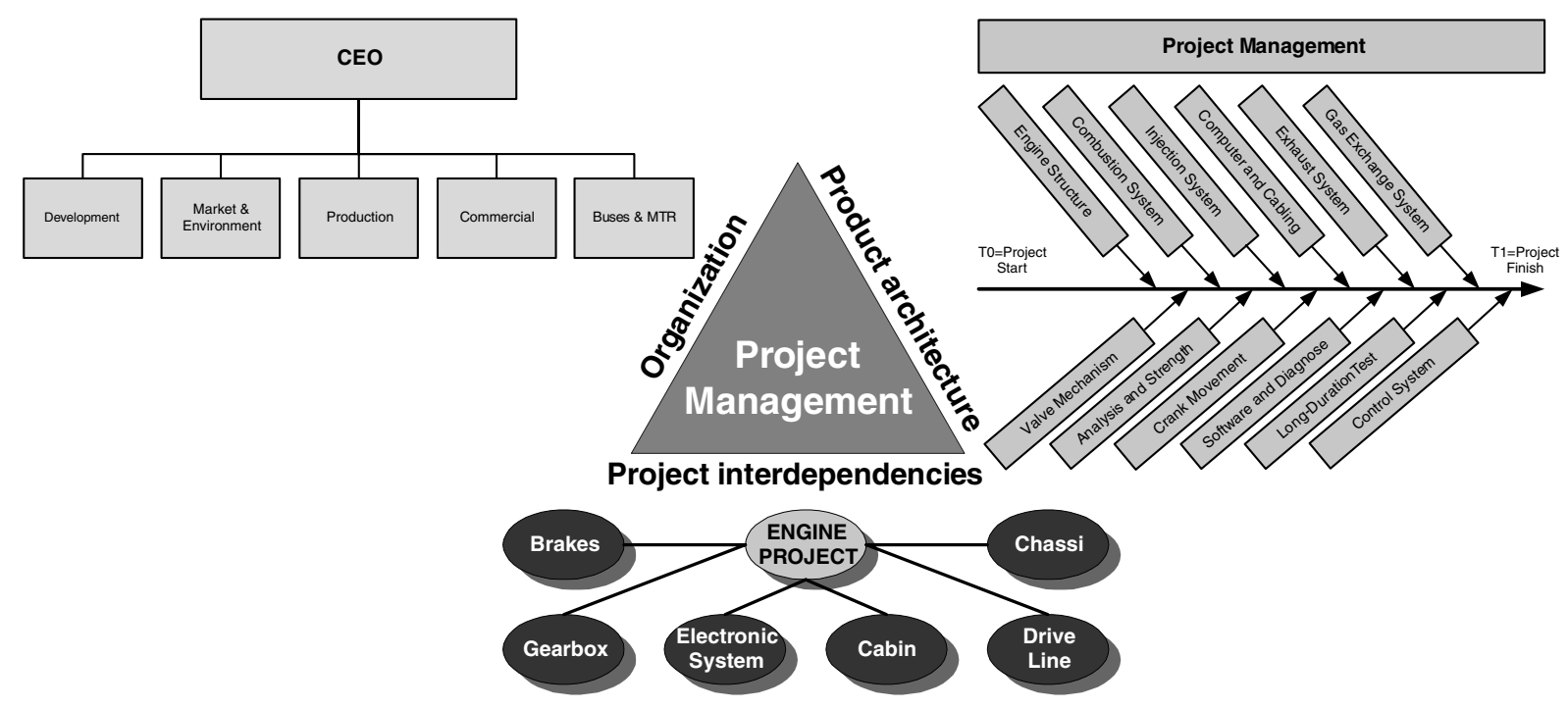

Fig. 3. Managing uncertainty in product development.

identified. In this case, interdependence was defined in terms of the need for information exchange in order to fulfill a task, WHO needs to communicate to WHOM in order to solve their tasks? WHAT kind of information need to be exchanged? WHY is this information exchange important to other people? WHEN should this information exchange take place? HOW should people involved share the needed information with each other in order to handle interdependencies?

After the workshop, the information recorded was analyzed and presented in DSM/DMM matrixes and analyzed. The DSM/DMM analyses were presented to all people and the outcome of this process was several communication plans ensuring that identified interdependencies were taken care as indicated above.

Following the above discussion, we have applied three different DSM analyses investigating interdependencies between the departments of the basic organization, within the project organization and between different projects in the multi-project situation. The focus was on the interdependencies related to the new engine project.

After data collection, identification, and mapping of interdependencies in the matrix, information is plotted in matrixes. Rows and columns are then altered in order to find clusters that are highly related to each other, departments within the basic organization, teams within the engine project, and between teams of the engine project and other projects. This analysis is supported by software tools that we have developed $[34,35]$. The search for patterns of interdependencies shows where the most critical intersections occur and point at those where special effort are needed in order to enable coordination.

In Fig. 4, we can see the two temporal DSM (top left and top right matrixes in Fig. 4) and one DMM (bottom matrix in Fig. 4) analyses when rows and columns are altered in order to identify clusters according to identified interdependencies. The numbers in the boxes indicate the level of dependencies identified. The number 3 signifies that the identified interdependence at a specific row and column intersection was of great importance, while the number 2 indicates a medium level and the number 1 a low level of interdependence. No numbers in row and column intersection signifies that no relevant dependence could be identified.

The top left-hand DSM identifies three clusters within the basic organization that are highly related to each other and that these departments have important interdependencies with respect to the engine project and top right-hand chart. The top-right hand DSM chart shows one large and one small cluster between teams within the engine project that are highly related to each other and thus require special concern. This chart also indicates two teams that are related to each other but much less than the others. The bottom DMM chart shows one major cluster of teams within the engine project and four other projects that are highly related to each other on the basis of a high level of interdependence. The outer cluster, shadowed area, indicates that six other teams have a high level of interdependence to eight projects, but less intense than that of the other three teams. This chart also indicates two projects that have few interdependencies to teams in this engine project. In addition, this chart shows that no teams and no other projects are completely independent and autonomous.

We can see from these DSM/DMM charts in Fig. 4 that there are a great number of interdependencies between physically oriented structures of the engine project, between this project and the basic organization, and between this engine project and more or less all other projects. 


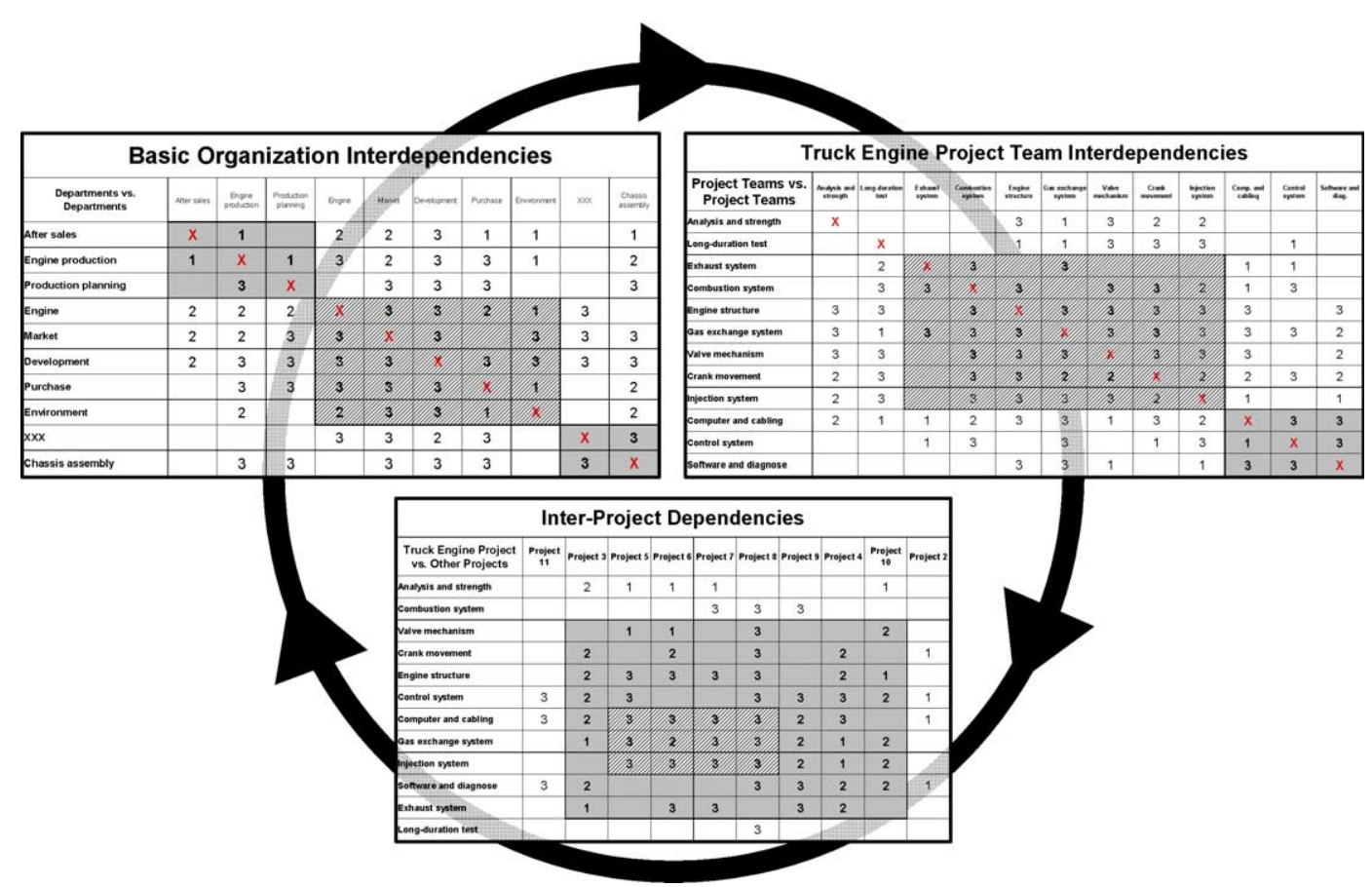

Fig. 4. Application of dependence structure matrix and domain mapping matrix in product development.

\section{Discussion}

As shown in Fig. 4, that no matter how we organize product development, there will always be intersections between departments, projects, teams, and individuals that are interdependent and need to share information with others. As we have noticed uncertainty and risk are related to the context and assumptions. The social constructionist perspective stress communication and information exchange to reduce the levels of uncertainty. Therefore, a participative approach is important and it has been used in this case both as a research approach and as impetus for influencing the real life of this truck manufacturing company. By definition, product development is an iterative process, but the iterations in the process of product development need to be minimized. Iterations are necessary as a consequence of changes in input information (upstream), updating of shared assumptions (concurrent), and discovery of errors (downstream), [25,37,38]. Mapping information dependence may reveal the underlying structure for systems engineering, and an organizational team setting can be designed on the basis of this structure. However, tasks, specifications, and interfaces change during product development or when new information is introduced. While product development is dynamic, the application of DSM or/and DMM are instant. In order to handle the dynamics of product development DSM and DMM analyses have to be done repeatedly [34]. The crucial questions, then, relate to how management and engineers involved in organizational and process design can deal with such uncertainty.
To confront these questions a systems approach is suggested starting with three major questions [14]:

- The first question is who is the designer of the system or the process?

- The second question concerns the system evolution and the processes of change.

- The third question considers the role of management.

The first question points out perhaps one of the most important issues related to traditional management approach, i.e., who is designing the system and the process in terms of organizational and project design. In this case, we introduced participative use of DSM and DMM and created a situation in which engineers supposed to perform the engineering work communicated their tasks with each other, discussed interdependencies, and needs for information exchange. In addition, they themselves were able to outline the design of this information exchange process. Thus, the organizing of the project became an issue engaging all involved and not only a few managers. The DSM analysis provided the enabling tool that created prerequisites for crucial communication.

The second question regards the nature of the system and its management. According to the systems approach of Buckley [14], we can infer that the product development process is equifinal. That means that the desired results may be reached by different trajectories with varying costs and time requirements. However, the process of organizing product development work or the project management is multifinal. The planning or the 
managerial process does not control the progress of the product development process. Different trajectories are likely to produce different outcomes. The consequences are that there are no ways to specify in advance a procedure that will guarantee the desired outcomes. A participative approach enables those involved to design the organization of the project and the means of communication to suit their needs for information exchange and interaction. The experiment showed that their individual ambitions to solve engineering problems were basedon knowledge that surpassed most of the managers'. By introducing participative DSM an arena for communication and mutual project design was created based on shared understanding of the present and the future situation.

The third question focuses on management and its role in this participative process. Westley [39] stresses that the structure and quality of the communication system is a key aspect. Management in a company can use strategic conversation, discrete communication about strategic generalities of the project according to overall goals and milestones and day-to-day activities between superior and subordinate, as a means of supporting and maintaining the dynamics of diverse social structures in collaborative settings. This process of inclusion creates mutual understandings, feeling of not being a stranger, brings clarity in areas of authority and responsibility, and helps to shed light on issues of boundary management. From being strangers, they now become companions and partners. The dialogue that was developed during problem-solving when conducting DSM and DMM analysis created mutual trust and tacit understanding between team members, promoting significant mutual responsibility, and collective commitment [40]. The communicative arena where participants from different departments and projects meet tries to balance loyalties to the members' disciplines while also maintaining a healthy respect for others. The strategic conversation is a vital mean of supporting the dynamic behavior of the company. In this strategic conversation, people can perceive the picture of the world, within and outside the project. During this conversation, people may influence the agenda and direction of management the project or change their own views. The aim of this strategic conversation is to find ways of integrating the subject (matter?) with the subjectivity and interpretations of people, substituting self-organizing based on purposeful sense making for the execution of power. This conversation needs to consider the diversity of people and their feelings of trust and integrity. In this respect, the management has the important role of creating an arena for communicating the strategic issues that they traditionally regard as their exclusive prerogatives. Strategic aspects well communicated will let the engineers see their role in the project and relate it to the big world. The outcome should be a shared understanding of what needs to be done and why.

\section{Conclusions}

In this paper, we have argued that the main sources of complexity in multi-project situations are the functionally demands of the products, the technologies chosen and the diversity of people involved. We took complexity as the analytical starting point, while uncertainty becomes the managerial issue. Only in trivial situations is a managerial control strategy based on planning effective, even when using the quite sophisticated DSM and DMM analysis as a tool. In the experiment realized in a real-life situation in a truck corporation, the DSM and DMM approach was used in a participatory way allowing all involved to discuss the project proposal and its organizing. The participants were able to improve on the analysis presented and contributed in designing a systematic means for communication. The combination of DSM and DMM analysis enabled the visualizing of interdependencies and relations and exploring the need for information exchange to reduce assumptions and uncertainty in product development.

Traditional DSM-analysis focus on dependencies and flow of information within one domain. These one domain analyses can be carried out in different domains simultaneously but these analysis do not reflect the dynamics of product development, the need for transformation of information in one domain in to another domain. In this paper, we introduce dual domain DMM-analysis that focus on the dynamics in product development in the sense that these analyses enables information in one domain to be depicted against some other or to be transformed into another domain. DMM-analysis enables the transformation of information between domains and by doing this the dynamics of the development process is explored, and information captured in one domain can be used in one another.

From management perspective, these dual DMManalysis in combination with one domain DSM-analysis provide managers with highly improved decision support and provide engineers with information of the total systems. From engineer's perspective, DSM and DMM analysis creates situational visibility, in which people can understand the context, interdependencies, and the need for information exchange. This reduces the uncertainty and risk, as people understand the situation. This leads to transparency within and between domains, i.e. with a project, between a project and the basic organization and between projects.

The most important outcomes of the participative DSM and DMM were that the management of 
uncertainty became a shared responsibility for engineers and managers. Everybody involved in the participative process have to be responsible for project organizing and problem solving, not only those formally assigned to a management position [41].

Direction for actions of people is now coming from the intensive interaction and understanding of the context and not from the orders of their managers. Direction does not come from their hierarchy but rather from the knowledge of the end customer's needs and business deals on an aggregate level and not only on their action level. Accountability was earlier related to what their own managers told them to do. Now accountability is coming from understanding strategic aspects of the whole business situation.

The experiment demonstrated as well the dynamic nature of a product development process. To reflect on the dynamics and uncertainty that change over time interdependency analyses by the DSM and DMM approach have to be repeated regularly. Probably one of the most important outcomes of this process is the learning that takes place through communicating, reflecting, understanding and finally acting.

\section{Acknowledgments}

We express our gratitude to two anonymous reviewers for their valuable comments on earlier versions of this paper, and Don Steward that was inspiring us in the work on DSM and development of DMM approach.

\section{References}

[1] von Hippel E. Task partitioning: an innovation process variable. Res Pol 1990;19:407-18.

[2] Pimmler TU, Eppinger SD. Integration analysis of product decompositions, Design theory and methodology - DTM'94, DE-Vol. 68. ASME; 1994.

[3] Ulrich KT, Eppinger SD. Product design and development. New York: McGraw-Hill, International Editions; 1994.

[4] Steward DV. A new business paradigm - information driven management, Napa, USA; 2000 [unpublished article].

[5] Adler N. Managing complex product development. Dissertation, Stockholm School of Economics, The Economic Research Institute, Stockholm; 1999.

[6] Cusumano MA, Nobeoka K. Thinking beyond lean. New York: The Free Press; 1998.

[7] Hendriks MHA, Voeten B, Kroep L. Human capacity allocation and project portfolio planning in practice. Int J Project Manage 1998;17(3):181-8.

[8] Grey RJ. Alternative approach to programme management. Int $\mathbf{J}$ Project Manage 1997;15(1):5-19.

[9] van der Merwe AP. Int J Project Manage 1997;15(4):223-33.

[10] Payne JH. Management of multiple simultaneous projects: a state-of-the-art review. Int J Project Manag 1995;13(3):163-8.

[11] Ghomi F, Ashjari B. A simulation model for multi-project resource allocation. Int J Project Manage 2002;20:127-30.
[12] Scott WR. Organizations: rational, natural, and open systems. Englewood Cliffs (NJ): Prentice-Hall; 1992.

[13] Perrow C. Complex organizations - a critical essay. New York: Random House; 1984.

[14] Buckley W. Sociology and modern systems theory. Englewood Cliffs (NJ): Prentice-Hall Inc; 1967.

[15] Simon H. Administrative behavior: a study of decision-making processes in administrative organization. New York: The Free Press; 1957.

[16] Simon HA. The architecture of complexity. Proc Am Philos Soc 1962;106:467-82.

[17] Simon HA. The science of the artificial. Cambridge, Boston: Massachusetts Institute of Technology Press, Massachusetts Institute of Technology; 1969.

[18] Bernstein PL. Against the god - the remarkable story of risk. Wiley; 1996.

[19] Wilson R. Analyzing the daily risks of life. Technol Rev 1979;81(4):41-6.

[20] Ross JF. The polar bear strategy - reflections on risk in modern life. Readings (MA): Perseus Books; 1999.

[21] Jamieson D. Scientific uncertainty: How do we know when to communicate research findings to the public?. Sci Total Environ 1996;184:103-7.

[22] Danilovic M. Loop - leadership and organization of integration in product development. Dissertation, Department of Management and Economics, Linköping University, Linköping; 1999.

[23] Steward D. 1967, The design structure systems, General Electric report no. 67APE6, San Jose, CA; 1967.

[24] Steward DV. The design structure system: a method for managing the design of complex systems. IEEE Trans Eng Manage 1981;28(3)

[25] Eppinger SD, Whitney DE, Smith RP, Gebala DA. A modelbased method for organizing tasks in product development, research in engineering design, vol. 6. London: Springer; 1994.

[26] Browning TR. Mechanisms for interteam integration: findings from five case studies. In Proceedings of the 7th international symposium of INCOSE, Los Angeles, August 3-7, 1997. p. 649 56.

[27] Eppinger SD, Whitney DE, Smith RP, Gebala DA. A modelbased method for organizing tasks in product development. Res Eng Des 1994;6(1):1-13.

[28] Morelli MM, Eppinger SD, Gulati RK. Predicting technical communication in product development organizations. IEEE Trans Eng Manage 1995;42(3).

[29] Kannapan SM, Bell DG, Taylor DL. Structuring information and coordinating teams in product development, Design theory and methodology, DE-vol. 53. ASME; 1993. p. 233-42.

[30] Browning TR. 1997, Exploring integrative mechanisms with a view toward design for integration, advances in concurrent engineering - CE97. In: Fourth ISPE International Conference on Concurrent Engineering: Research and Applications, August 20-22, 1997.

[31] Browning TR. Applying the design structure matrix to system decomposition and integration problems: a review and new directions. IEEE Trans Eng Manage 2001;48(3).

[32] Danilovic M, Browning T. A formal approach for domain mapping matrices (DMM) to complement design structure matrices (DSM). In: Proceedings of the sixth design structure matrix (DSM) international workshop. September 12-14th, 2004. Cambridge, UK: Trinity Hall College, University of Cambridge, Cambridge Engineering Design Centre; 2004.

[33] Danilovic M. Supplier integration in product development. In: Proceedings of the 10th international annual IPSERA conference, April 8-11, 2001. Jönköping, Sweden: Jönköping University, Jönköping International Business School; 2001a. p. 25365. 
[34] Danilovic M. Managing multiproject environment. In: Proceedings of the 3rd international dependence structure matrix (DSM) workshop, October 29-30, 2001. Massachusetts, Boston, Cambridge, USA: Massachusetts Institute of Technology (MIT); $2001 \mathrm{~b}$.

[35] Danilovic M, Sigemyr T. Multi domain based DSM tool. In: Proceedings of the 5th dependence structure matrix (DSM) international workshop, October 22-23, 2003, Cambridge, UK: University of Cambridge, Cambridge, EngineeringDesignCentre; 2003.

[36] Maurer M, Pulm U, Lindeman U. Tendencies towards more and more flexibility. In: Proceedings of the 5 th dependence structure matrix (DSM) international workshop, October 22-23, 2003. Cambridge, UK: University of Cambridge, Cambridge, Engineering Design Centre; 2003.
[37] Smith RP, Eppinger SD, Gopal A. Testing an engineering design iteration model in an experimental setting, Design theory and methodology, DE-Vol. 42. ASME; 1992. p. 269-76.

[38] Smith RP, Eppinger SD. Identifying controlling features of engineering design iteration. Manage Sci 1997;43(3).

[39] Westley FR. Middle managers and strategy: microdynamics of inclusion. Strategic Manage J 1990:337-51.

[40] O'Reilly C, Chatman J. Organizational commitment and psychological attachment: the effects of compliance, identification, and internalization on prosocial behavior. J Appl Psychol 1986;71(3):492-9.

[41] Nonaka I, Takeuchi H. The knowledge-creating company - how japanese companies create the dynamics of innovation. New York: Oxford University Press; 1995. 